\title{
REPORTING OF WORKPLACE VIOLENCE TOWARDS NURSES IN 5 EUROPEAN COUNTRIES - A CROSS-SECTIONAL STUDY
}

\author{
BEATA BABIARCZYK ${ }^{1}$, AGNIESZKA TURBIARZ², MARTINA TOMAGOVÁ ${ }^{3}$, RENÁTA ZELENÍKOVÁ4, \\ EBRU ÖNLER ${ }^{5}$, and DAVID SANCHO CANTUS ${ }^{6}$
}

\author{
${ }^{1}$ University of Bielsko-Biala, Bielsko-Biała, Poland \\ Faculty of Health Sciences, Department of Nursing \\ ${ }^{2}$ Slettebakken Menighets Eldresenter, Bergen, Norway \\ ${ }^{3}$ Comenius University in Bratislava, Bratislava, Slovak Republic \\ Jessenius Faculty of Medicine in Martin, Department of Nursing \\ ${ }^{4}$ University of Ostrava, Ostrava, Czech Republic \\ Faculty of Medicine, Department of Nursing and Midwifery \\ ${ }^{5}$ Namik Kemal University, Tekirdağ, Turkey \\ School of Health, Department of Nursing \\ ${ }^{6}$ Universidad Católica de Valencia, Valencia, Spain \\ Faculty of Nursing
}

\begin{abstract}
Objectives: This study aimed to assess country-specific evidence of physical and non-physical acts of workplace violence towards nurses working in the health sector in 5 European countries, and then to identify reasons for not reporting violence experienced at work. Material and Methods: This retrospective cross-sectional study was conducted in 5 participating countries (Poland, the Czech Republic, the Slovak Republic, Turkey, and Spain). All registered nurses working in selected healthcare settings for at least 1 year were invited to participate in the study. A questionnaire adapted from the Workplace Violence in the Health Sector Country Case Study - Questionnaire, developed jointly by the International Labour Office, the International Council of Nurses, the World Health Organization and Public Services International, was used. The selection of healthcare settings and the distribution of the questionnaire were conducted according to the recommendations of the questionnaire authors. Results: In total, 1089 nurses submitted completed questionnaires which could be included in the study. Of these, $54 \%$ stated that they had been exposed to non-physical violence and $20 \%$ had been exposed to physical violent acts. A total of $15 \%$ of the surveyed nurses experienced both forms of workplace violence. In addition, $18 \%$ of the respondents confirmed having witnessed physical violence in their workplace. The most common perpetrators were patients and patients' relatives. In about $70 \%$ of these cases, no actions were taken after the act of violence to investigate its causes. About half of the study group did not report workplace violence as they believed it was useless or not important. The most common consequences of workplace violence included being "superalert" or watchful and on guard. Conclusions: Nurses internationally are both victims of and witnesses to workplace violence. Workplace violence is often seen by nurses as an occupational hazard and, as such, it remains not reported. The first step in preventing workplace violence is not only to acknowledge its existence but also to ensure the appropriate reporting of violent acts. Int J Occup Med Environ Health. 2020;33(3):325-38
\end{abstract}

Key words:

occupational health, nurse, physical violence, perpetrators, verbal abuse, reasons for non-reporting

Received: May 7, 2019. Accepted: January 30, 2020.

Corresponding author: Beata Babiarczyk, University of Bielsko-Biala, Faculty of Health Sciences, Department of Nursing, Willowa 2, 43-309 Bielsko-Biała, Poland (e-mail: bbabiarczyk@ath.bielsko.pl) 


\section{INTRODUCTION}

The increasing rates of violence in the health sector, which have been observed in recent decades, are a reflection of the growing problem of aggression in the society as a whole, according to literature data. We all live in a violent world; people are in a constant hurry and experience stress overload, even in situations which do not normally cause stress. Patients, who are increasingly more aware of their rights and have high expectations, often face a malfunctioning healthcare system with its understaffing, poor funding and high workload of the personnel. This, in turn, can generate dissatisfaction, frustration and a feeling of injustice, all leading to an escalation in aggression [1,2].

Analyses have shown that the healthcare and social work sectors have a very high prevalence of workplace violence [3]. Nurses play a central role within healthcare teams, and often work at the front line interacting with all kinds of patients. They also constitute one of the professional groups which are the most vulnerable to acts of violence. Unfortunately, the actual data about violence towards nurses does not exist as the majority of acts of violence often remain concealed.

For various reasons, nurses do not report every occurrence of incidents of violence [4]. The absence of an efficiently functioning national reporting system in most countries can be one of the obstacles. Defining what represents an acceptable form of behavior in a given socio-cultural context can also remain vague. Furthermore, acts of violence may be seen by nurses as an occupational hazard [5-8].

The proportion of companies in the participating countries that have established procedures to deal with workrelated violence is among the lowest in Europe. Violence and harassment are usually not considered to be a major issue in these countries. The awareness is still low or is slowly increasing, and policies and procedures are only now developing or do not yet exist [3].
In 2002, the World Health Organization (WHO), together with the International Council of Nurses (ICN), the International Labour Office (ILO) and Public Services International (PSI), launched a program aimed at establishing policies and practical standards for the prevention and elimination of violence in the health sector. According to the definition developed by this coalition, physical violence stands for "the use of physical force against another person or group, which results in physical, sexual or psychological harm, such as beating, kicking, slapping, stabbing, shooting, pushing, biting, and/or pinching, among others," while psychological violence is defined as "intentional use of power, including the threat to use physical force against another person or group that can result in harm to physical, mental, spiritual, moral or social development." Psychological violence includes verbal abuse, bullying/mobbing, harassment and threats [9]. These 2 definitions were used in this study.

Data from the countries participating in this study regarding workplace violence in the health sector has up until now been sparse. This study, therefore, aims to explore country-specific evidence of physical and non-physical acts of workplace violence towards nurses working in the health sector in 5 European countries, and then to identify the reasons for not reporting violence experienced at work.

\section{MATERIAL AND METHODS}

\section{Sample and procedure}

The retrospective cross-sectional survey was conducted in June-November 2016 in 5 participating countries (Poland, the Czech Republic, the Slovak Republic, Turkey, and Spain). All registered nurses working in selected healthcare settings for at least 1 year were invited to participate in the study. The selection of healthcare settings and the distribution of the questionnaire were conducted according to the following recommendations of the questionnaire authors: 
- distribution to staff of health facilities and work settings in a major city in the country;

- within a chosen urban area, all major healthcare settings that represent the national health system should be covered, i.e., staff working in tertiary and secondary hospitals, in primary institutions - healthcare centres, clinics, community health centres, outreach services, rehabilitation centres, nursing homes, or homes for the elderly;

- all major disciplines should be covered within the healthcare settings, i.e., general medicine, surgery, emergency care, psychiatry, pediatrics, etc.;

- all hierarchy levels within institutions should be included [9].

Obtaining approval from private healthcare providers proved to be difficult, so these institutions were not included in the study sample. Due to the small number of participants working in some of the studied health system areas, in contrast to the basic ILO/ICN/WHO/PSI questionnaire, the authors chose to combine the following areas:

- general medicine, general surgery, intensive care, operating theatre, specialized units and endoscopy units grouped together as the "hospital unit" (73\%);

- ambulatory care, health centres and community/district clinics (10\%);

- emergency care and ambulance services (8\%);

- hospices, homes for the elderly/nursing homes and rehabilitation centres/convalescent homes (5\%);

- psychiatric care (4\%) and management (1\%) - considered as separate workplaces.

When completing the questionnaire, the nurses gave their informed consent for participation in the study. However, they were assured that they could withdraw from the study at any time. The anonymity of all participants and the confidentiality of their responses were also ensured. The study was performed in accordance with the ethical standards laid down in the Declaration of Helsinki and approved, whenever required, by the local ethics committee.

\section{Measures}

For the purpose of this study, a slightly modified version of the ILO/ICN/WHO/PSI Workplace Violence in the Health Sector Country Case Study - Questionnaire [10] was used. An appropriate permission to use the survey questionnaire was obtained from the ILO Publications Bureau. The baseline version of the questionnaire was translated into the participants' languages. According to the applicable recommendations for the cross-cultural adaptation of the study instruments, 2 independent translations, forward-translation and back-translation, as well as panel discussions were performed by each of the participating research teams [11]. Unlike the original version of the questionnaire, the authors decided to exclude the issues of bullying/mobbing, sexual harassment and racial harassment from this study. After adjustments, the questionnaire was composed of 5 main sections:

- personal and workplace data (16 items),

- physical workplace violence (20 items),

- psychological workplace violence (12 items),

- data about the health sector ( 2 items),

- opinions on workplace violence (3 items).

This article presents data obtained from sections 1-3.

As the authors addressed their survey only to nurses, section 1 of the original survey questionnaire was adjusted accordingly (questions PD6, PD7, PD15). Moreover, question PD7 was removed since the private sector was not included in the study. The internal consistency for the questionnaire was good (Cronbach's $\alpha \geq 0.83$ ). Each questionnaire was accompanied by a covering letter, in which the participants were informed about the purpose of the study, and by a glossary of terms. The participants were informed that the study limited its focus to different forms of physical violence, verbal abuse and threats. Compared to the original version of the questionnaire, the authors decided not to look into the problem of bullying/mobbing, sexual harassment or racial harassment. 


\section{Data analysis}

The data was analysed and verified statistically using PQStat 1.6.4 and PSPP 0.10.4 software. All features were quantitative and were presented with the arithmetic mean and standard deviation. The $\chi^{2}$ test and Fisher's exact test were used to assess the differences between the groups of independent variables. P-values of $<0.05$ were considered significant.

\section{RESULTS}

In total, 1089 nurses (Poland: $\mathrm{N}=265$; the Czech Republic: $\mathrm{N}=324$, the Slovak Republic: $\mathrm{N}=200$; Turkey: $\mathrm{N}=$ 200, and Spain: $N=100$ ) submitted completed questionnaires which could be included in the study. A description of the study participants by country is presented in Table 1.

Overall, $69 \%$ of the study participants indicated that some procedures for reporting violence were in force in their workplace; significantly, this included a higher percentage of Czech nurses (88\%) and Turkish nurses (83\%), compared with only $32 \%$ of nurses from the Slovak Republic $(\mathrm{p}<0.001)$. However, only $23 \%$ of all nurses knew how to use such procedures. Nearly half of the study group confirmed that they were encouraged to report workplace violence. However, this was significantly more often declared by nurses from the Czech Republic (79\%) and Spain (63\%), compared with only a third of the study participants from both Poland and the Slovak Republic $(\mathrm{p}<0.001)$.

On a 1-5 scale (1 - "not worried at all"; 5 - "very worried"), the study participants estimated the extent to which they were worried about violence in their current workplace. The highest scores were given by nurses on psychiatric wards $(3.31 \pm 1.0)$ and in emergency/ambulance departments (3.02 \pm 1.2$)$. In particular, Czech and Slovak nurses working in the above mentioned work settings confirmed a high level of anxiety $(p<0.001)$. The analysis showed that significantly more study participants who had previ- ously been physically attacked and/or verbally abused in their workplace were either "very worried" or "somewhat worried" about violence, compared with those who had not been attacked $(\mathrm{p}<0.001)$.

\section{Non-physical workplace violence}

The most common form of workplace violence was psychological violence. Out of 1089 study participants, 54\% stated that they had been exposed to non-physical violence in the past 12 months. Most of them stated that the incident could not have been prevented. There was a significant relationship between the frequency of nonphysical violence and the countries and work settings. The fact of being verbally attacked was far less frequently reported by Spanish nurses (34\%), compared with all the other countries $(\mathrm{p}<0.001)$. Taking into account the various work settings, $87 \%$ of psychiatric nurses and $67 \%$ of nurses working in emergency and ambulance services significantly more often confirmed being exposed to verbal abuse, compared with other work settings $(\mathrm{p}<0.001)$.

\section{Physical workplace violence}

Overall, $20 \%$ of the respondents reported being exposed to physical workplace violence in the past 12 months. With regard to the frequency of physical violence, it was found that Polish nurses (34\%) and Slovak nurses (21\%) significantly more often reported being physically attacked, compared with only $8 \%$ of Turkish nurses $(\mathrm{p}<0.001)$. As far as work settings are concerned, the respondents working on psychiatric wards (36\%) and in hospices, homes for the elderly/nursing homes and rehabilitation centres/convalescent homes (32\%) significantly more often experienced physical attacks, compared with only $9 \%$ of nurses working in ambulatory, health centre and community/district settings ( $\mathrm{p}<0.001)$.

A total of $15 \%$ of the surveyed nurses experienced both forms of workplace violence. 
Table 1. Description of the study population by country - based on the survey conducted among nurses in 5 participating countries: Poland, the Czech Republic, the Slovak Republic, Turkey, and Spain, in June-November 2016

\begin{tabular}{|c|c|c|c|c|c|}
\hline \multirow[t]{2}{*}{ Variable } & \multicolumn{5}{|c|}{$\begin{array}{c}\text { Participants } \\
{[\mathrm{n}(\%)]} \\
(\mathrm{N}=1089)\end{array}$} \\
\hline & $\begin{array}{l}\text { Poland } \\
(\mathrm{N}=265)\end{array}$ & $\begin{array}{l}\text { Czech Republic } \\
\quad(\mathrm{N}=324)\end{array}$ & $\begin{array}{l}\text { Slovak Republic } \\
\quad(\mathrm{N}=200)\end{array}$ & $\begin{array}{c}\text { Turkey } \\
(\mathrm{N}=200)\end{array}$ & $\begin{array}{c}\text { Spain } \\
(\mathrm{N}=100)\end{array}$ \\
\hline \multicolumn{6}{|l|}{$\overline{\operatorname{Sex}}$} \\
\hline female & $263(99)$ & $300(93)$ & $195(97)$ & $167(83)$ & $81(81)$ \\
\hline male & $2(1)$ & $24(7)$ & $5(3)$ & $33(17)$ & $19(19)$ \\
\hline \multicolumn{6}{|l|}{ Age } \\
\hline 20-24 years & $14(5)$ & $26(8)$ & $20(10)$ & $79(39)$ & $4(4)$ \\
\hline $25-29$ years & $27(10)$ & $42(13)$ & $12(6)$ & $73(36)$ & $15(15)$ \\
\hline 30-34 years & $9(3)$ & $46(14)$ & $20(10)$ & $34(17)$ & $18(18)$ \\
\hline $35-39$ years & $19(7)$ & $56(17)$ & $30(15)$ & $10(5)$ & $21(21)$ \\
\hline 40-44 years & $52(20)$ & $56(17)$ & $20(10)$ & $2(1)$ & $6(6)$ \\
\hline $45-49$ years & $68(26)$ & $40(12)$ & $30(15)$ & 0 & $15(15)$ \\
\hline $50-54$ years & $51(19)$ & $28(9)$ & $33(17)$ & 0 & $5(5)$ \\
\hline $55-59$ years & $21(8)$ & $22(7)$ & $31(15)$ & $1(1)$ & $12(12)$ \\
\hline$\geq 60$ years & $4(2)$ & $8(2)$ & $4(2)$ & $1(1)$ & $4(4)$ \\
\hline \multicolumn{6}{|l|}{ Marital status $(\mathrm{N}=1086)^{*}$} \\
\hline single & $52(20)$ & $65(20)$ & $41(21)$ & $122(61)$ & $19(19)$ \\
\hline married & $176(66)$ & $179(56)$ & $134(67)$ & $73(36)$ & $57(57)$ \\
\hline living with a partner & $11(4)$ & $33(10)$ & $2(1)$ & $3(1)$ & $19(19)$ \\
\hline widow/widower & $7(3)$ & $37(12)$ & $11(5)$ & $1(1)$ & $4(4)$ \\
\hline separated /divorced & $18(7)$ & $8(2)$ & $12(6)$ & $1(1)$ & $1(1)$ \\
\hline \multicolumn{6}{|l|}{ Job position $(\mathrm{N}=1082)^{*}$} \\
\hline manager & $4(1)$ & $3(1)$ & 0 & 0 & 0 \\
\hline head nurse & $21(8)$ & $7(2)$ & $16(8)$ & 0 & $6(6)$ \\
\hline nurse & $238(90)$ & $237(74)$ & $183(92)$ & $199(99)$ & $86(86)$ \\
\hline other (charge nurse) & $1(1)$ & $72(23)$ & 0 & $1(1)$ & $8(8)$ \\
\hline \multicolumn{6}{|c|}{ Work experience in the health sector } \\
\hline $1-5$ years & $35(13)$ & $61(19)$ & $38(19)$ & $116(58)$ & $24(24)$ \\
\hline $6-10$ years & $23(9)$ & $53(16)$ & $32(16)$ & $59(30)$ & $21(21)$ \\
\hline $11-15$ years & $15(6)$ & $43(13)$ & $13(6)$ & $18(9)$ & $23(23)$ \\
\hline $16-20$ years & $33(12)$ & $51(16)$ & $17(9)$ & $5(2)$ & $10(10)$ \\
\hline$>20$ years & $159(60)$ & $116(36)$ & $100(50)$ & $2(1)$ & $22(22)$ \\
\hline
\end{tabular}

* The difference between the number of participants is due to the lack of responses given. 


\section{Perpetrators of violence}

The most common perpetrators, according to the respondents, were patients (70\% of the sources of verbal abuse, and $92 \%$ of the sources of physical attacks) and patients' relatives (40\% of the sources of verbal abuse, and $10 \%$ of the sources of physical attacks). Lateral violence, originating from staff members, managers/supervisors or external colleagues/workers was less frequently reported. A total of $16 \%$ of the respondents experienced non-physical lateral violence while $3.7 \%$ experienced physical lateral violence. However, statistically significant differences between the countries were found regarding the reported perpetrators; nurses from Turkey were more often exposed to verbal abuse (73\%) and physical attacks (47\%) from patients' relatives, while all the other nurses significantly more often reported patients as the source of violence $(\mathrm{p}<0.001)$. The work setting in which the nurses were employed also influenced their responses. More specifically, $94 \%$ of nurses on psychiatric wards and $83 \%$ of nurses in hospices, homes for the elderly/nursing homes and rehabilitation centres/convalescent homes experienced significantly more often verbal abuse from patients, compared with other perpetrators ( $p<0.001)$. Moreover, patients were reported as the source of physical attack by $100 \%$ of psychiatric nurses, while patients' relatives - by $100 \%$ of management nurses $(\mathrm{p}<0.01)$.

\section{Responses towards workplace violence and reporting of violent incidents}

Responses towards workplace violence are presented in Table 2. Action taken after verbal abuse to investigate the causes of violence was more frequent in Turkey (23\%), and less frequent in the Czech Republic (9\%) and Spain $(9 \%)(\mathrm{p}<0.01)$. Moreover, the data analysis showed that nurses aged 50-54 years more often confirmed that such action had been taken, compared with respondents aged $\geq 60$ years ( $p<0.01)$. It was also found, on the basis of reports by Spanish nurses, that action had never been taken to investigate the causes of physical assaults, in contrast to frequent investigations in other countries $(\mathrm{p}<0.01)$. With regard to the reasons given for not reporting verbal abuse, as presented by country in Table 3 , statistically significant differences between work settings and age groups were also found. The majority of psychiatric nurses (78\%), as well as $73 \%$ of nurses from hospices, homes for the elderly/nursing homes and rehabilitation centres/convalescent homes stated that it was not important to report verbal abuse ( $\mathrm{p}<0.001)$. Furthermore, $50 \%$ of nursing managers felt ashamed about verbal abuse and this shame was the reason for non-reporting $(\mathrm{p}<0.01)$. Significantly more nurses working in different hospital units (61\%), and in emergency or ambulance services (62\%), stated that reporting violence would be "useless" ( $p<0.001$ ). As far as the differences between the age groups are concerned, $16 \%$ of nurses aged $50-54$ years stated they had felt ashamed, compared with none in the age groups of 20-24 and $>60(p<0.01)$. Moreover, nurses aged 20-24 years and $\geq 60$ years significantly more often had no information about who they could report verbal abuse to $(\mathrm{p}<0.01)$.

The analysis showed that the reasons given for incidents of physical attacks being neither reported nor discussed with others varied between the countries under analysis (Table 3). The reasons given for not reporting abuse were not significantly affected by other variables ( $p>0.05)$.

The most common consequence of workplace violence was, according to the respondents, being "super-alert" or watchful and on guard (physical assault - 81\%; verbal abuse $-71 \%$ ). When asked about being a witness to physical violence in the workplace, $18 \%$ of the respondents confirmed this fact, with significantly more psychiatric nurses $(51 \%)$ compared to other nurses ( $p<0.001)$.

\section{DISCUSSION}

This study confirms that nurses internationally are both victims of and witnesses to workplace violence. Workplace violence is a multidimensional problem that affects 
Table 2. Responses and consequences to workplace violence incidents - based on the survey conducted among nurses in 5 participating countries: Poland, the Czech Republic, the Slovak Republic, Turkey, and Spain, in June-November 2016

\begin{tabular}{|c|c|c|}
\hline \multirow[t]{2}{*}{ Variable } & \multicolumn{2}{|c|}{$\begin{array}{c}\text { Cases } \\
{[\mathrm{n}(\%)]}\end{array}$} \\
\hline & physical violence & non-physical violence \\
\hline \multicolumn{3}{|l|}{ Response* } \\
\hline took no action & $9(4)$ & $84(14)$ \\
\hline tried to pretend it had never happened & $16(7)$ & $62(11)$ \\
\hline told the person to stop & $124(58)$ & $346(59)$ \\
\hline tried to defend oneself (physically/verbally) & $41(19)$ & $23(4)$ \\
\hline told friends/family & $53(25)$ & $100(17)$ \\
\hline sought counselling & $6(3)$ & $18(3)$ \\
\hline told a colleague & $109(51)$ & $284(48)$ \\
\hline reported it to a senior staff member & $112(52)$ & $179(30)$ \\
\hline transferred to another position & $3(1)$ & $10(2)$ \\
\hline sought help from the nurses association & $1(1)$ & $5(1)$ \\
\hline sought help from the union & $4(2)$ & $5(1)$ \\
\hline completed an incident/accident form & $27(13)$ & $30(5)$ \\
\hline pursued prosecution & $2(1)$ & $1(1)$ \\
\hline completed a compensation claim & 0 & 0 \\
\hline other (handed in resignation) & 0 & $9(1)$ \\
\hline \multicolumn{3}{|l|}{ Time off taken from work due to the attack } \\
\hline yes & $3(1)$ & 0 \\
\hline no & $209(99)$ & $576(100)$ \\
\hline \multicolumn{3}{|l|}{ Action taken to investigate the causes of violence } \\
\hline yes & $34(16)$ & $80(14)$ \\
\hline no & $146(70)$ & $434(75)$ \\
\hline do not know & $29(14)$ & $62(11)$ \\
\hline \multicolumn{3}{|l|}{ Source for taking action* } \\
\hline victim & $16(50)$ & $12(15)$ \\
\hline management/employer & $18(56)$ & $58(72)$ \\
\hline union & 0 & $8(10)$ \\
\hline nurses association & $1(13)$ & $1(1)$ \\
\hline police & $4(13)$ & $1(1)$ \\
\hline other (colleague) & $1(13)$ & 0 \\
\hline \multicolumn{3}{|l|}{ Consequences for the attacker* } \\
\hline none & $9(27)$ & $25(32)$ \\
\hline verbal warning issued & $12(35)$ & $39(50)$ \\
\hline care discontinued & 0 & $11(14)$ \\
\hline reported to the police & $3(9)$ & $1(1)$ \\
\hline
\end{tabular}


Table 2. Responses and consequences to workplace violence incidents - based on the survey conducted among nurses in 5 participating countries: Poland, the Czech Republic, the Slovak Republic, Turkey, and Spain, in June-November 2016 - cont.

\begin{tabular}{|c|c|c|}
\hline \multirow[t]{2}{*}{ Variable } & \multicolumn{2}{|c|}{$\begin{array}{c}\text { Cases } \\
{[\mathrm{n}(\%)]}\end{array}$} \\
\hline & physical violence & non-physical violence \\
\hline \multicolumn{3}{|l|}{ Consequences for the attacker* - cont. } \\
\hline aggressor prosecuted & $1(3)$ & $1(1)$ \\
\hline other (treatment modification) & $10(30)$ & 0 \\
\hline do not know & $2(6)$ & $4(5)$ \\
\hline \multicolumn{3}{|c|}{ Satisfaction with the manner in which the violence incident was handled } \\
\hline very dissatisfied & $4(12)$ & $14(18)$ \\
\hline dissatisfied & $10(29)$ & $21(26)$ \\
\hline moderately dissatisfied & $14(41)$ & $22(27)$ \\
\hline satisfied & $3(9)$ & $20(25)$ \\
\hline very satisfied & $3(9)$ & $3(4)$ \\
\hline
\end{tabular}

* Multiple answers allowed.

Table 3. Reasons for not reporting the incidents of attack by country - based on the survey conducted among nurses in 5 participating countries: Poland, the Czech Republic, the Slovak Republic, Turkey, and Spain, in June-November 2016

\begin{tabular}{|c|c|c|c|c|c|c|c|}
\hline \multirow{2}{*}{ Reason* } & \multicolumn{6}{|c|}{$\begin{array}{c}\text { Participants' answers } \\
{[\mathrm{n}(\%)]}\end{array}$} & \multirow{2}{*}{$\mathrm{p}$} \\
\hline & total & Poland & $\begin{array}{c}\text { Czech } \\
\text { Republic }\end{array}$ & $\begin{array}{c}\text { Slovak } \\
\text { Republic }\end{array}$ & Turkey & Spain & \\
\hline \multicolumn{8}{|l|}{ Non-physical attack } \\
\hline it was not important & $151(41)$ & $31(27)$ & $49(59)$ & $38(51)$ & $18(21)$ & $15(71)$ & $<0.001^{\mathrm{a}}$ \\
\hline felt ashamed & $15(4)$ & $9(8)$ & $4(5)$ & 0 & 0 & $2(10)$ & $<0.01^{\mathrm{b}}$ \\
\hline felt guilty & $1(1)$ & $1(1)$ & 0 & 0 & 0 & 0 & n.s. \\
\hline useless & $204(55)$ & $78(72)$ & $32(38)$ & $35(47)$ & $58(69)$ & $1(5)$ & $<0.001^{\circ}$ \\
\hline afraid of negative consequences & $31(8)$ & $9(8)$ & $8(10)$ & $4(5)$ & $6(7)$ & $4(19)$ & n.s. \\
\hline did not know who to report to & $14(4)$ & $5(5)$ & 0 & $1(1)$ & $6(7)$ & $2(9)$ & n.s. \\
\hline \multicolumn{8}{|l|}{ Physical attack } \\
\hline it was not important & $46(42)$ & $21(42)$ & $7(43.8)$ & $10(44)$ & 0 & $8(89)$ & $<0.01^{\mathrm{a}}$ \\
\hline felt ashamed & $3(4)$ & $3(6)$ & 0 & $1(4)$ & 0 & 0 & n.s. \\
\hline felt guilty & $1(1)$ & 0 & 0 & $1(4)$ & 0 & 0 & n.s. \\
\hline useless & $58(53)$ & $22(44)$ & $9(56.3)$ & $14(61)$ & $12(100)$ & $1(11)$ & $<0.001^{\mathrm{b}}$ \\
\hline afraid of negative consequences & $6(6)$ & $2(4)$ & 0 & $1(4)$ & $3(25)$ & 0 & $<0.01^{\mathrm{c}}$ \\
\hline did not know who to report to & $4(4)$ & $3(6)$ & 0 & $1(4)$ & 0 & 0 & n.s. \\
\hline
\end{tabular}

n.s. - statistically non-significant.

* Multiple answers allowed.

${ }^{\mathrm{a}}$ Value of $\chi^{2}$ test $=43.32, \mathrm{df}=4 ;{ }^{\mathrm{b}} \chi^{2}=13.50, \mathrm{df}=4{ }^{\mathrm{c}} \chi^{2}=51.93, \mathrm{df}=4$. 
the employee, the employer and patients. Some researchers report that patients' aggression towards nurses is associated with nurses' decisions to leave their jobs or even the nursing profession [12,13]. Moreover, it is often considered as an economic burden due to the costs related to increased turnover, absenteeism, medical and psychological care, property damage, job dissatisfaction, and decreased morale $[14,15]$. Nurses admit that, after experiencing violence, they are afraid and tend to avoid patients who have been or might be violent, which results in a lower quality of care [16-19].

The results of this study confirmed that nurses who had experienced acts of violence were significantly more worried about violence, compared with those who had not been attacked. Furthermore, Magnavita reported in his study [20] that stress caused by experienced violence, especially if combined with excessive workload or with a feeling of insufficient control over work tasks, could in turn expose an employee to acts of violence. The author concluded that, in order to avoid violent acts in the workplace, besides prevention programs, the workers should be offered interventions to reduce occupational stress and to learn coping strategies.

There are several countries which have developed and begun to implement coordinated strategies such as a "zero tolerance zone" for the prevention of workplace violence in the health sector. Although, from the legal point of view, all such guidelines are advisory in nature, they refer to the relevant occupational health and safety legislation. However, in the review by Chirico et al. [21], which aimed to evaluate occupational safety and health $(\mathrm{OSH})$ regulatory frameworks developed by various countries around the world, it was shown that most countries (64\%) have not included mandatory workplace violence prevention and psychosocial hazard assessments in their OSH legislation. All EU members registered in the Global Database on Occupational Safety and Health Legislation (LEGOSH) explicitly or implicitly included psychosocial hazards and workplace violence in their OSH regulations. The authors confirmed that, with regard to Polish and Spanish legislation (only these 2 among the participating countries were registered in LEGOSH), no explicit regulations concerning the prevention of workplace violence were demonstrated. In Poland, the OSH regulations include only mobbing as a psychosocial hazard, with no information about other forms of workplace violence. In Spanish law, there is no data available on psychosocial risks, but legislation does consider discrimination and harassment as very serious infringements.

Regarding general legal regulations protecting healthcare workers (including nurses) from aggression, there are some regulations in all 5 countries involved in the study. In some of the participating countries (Poland, the Czech Republic), nurses are under extra legal protection; there are stricter criminal penalties for assaults on nurses. However, all of these countries lack effective guidelines for the health sector workplaces regarding protection at the national level against workplace violence.

There is a popular belief that the current reporting tools are too cumbersome and time-consuming to be used, whereas nurses need a simple system so as to be able to report violence immediately. The first step in preventing workplace violence is not only to acknowledge its existence, but also to ensure the appropriate reporting of violent acts. Incidents of violence must be systematically documented using a reporting system developed by government authorities and health institutions. Subsequent steps might include implementing a violence prevention program, for example, like the one reported on by the authors in Italy [20], which includes educational, organizational and medical measures that contribute significantly to reducing the risk of violence in the workplace.

The results of this study suggest that workplace violence, especially non-physical, is indeed a problem for nurses internationally [3]. Overall, 54\% of the study participants had experienced non-physical violence, and $20 \%$ had 
been exposed to physical attacks in their work settings in the past 12 months. One-third of the participants had, in turn, experienced both types of workplace violence. These findings are in line with other studies on violence towards nurses [19,22-25]. Furthermore, nurses are not only victims of, but often also witnesses to, violent acts (18\% of the participants had witnessed violent incidents in their workplaces, this fact being particularly confirmed by psychiatric nurses).

The results of this study are also in line with the growing body of literature about the work settings most frequently characterised by workplace violence. Settings such as psychiatric wards, emergency services or nursing homes were found to be at a higher risk of workplace violence $[6,15,26,27]$. Similar to other findings presented in the literature, this study confirmed that working in psychiatric wards and emergency/ambulance services was an important risk factor in terms of being exposed to verbal abuse. The rate of violent physical acts was also the highest on psychiatric wards as well as in hospices, homes for the elderly/nursing homes and rehabilitation centres/convalescent homes. Contrasting, yet very interesting, findings in this area were published by Schablon et al. [19]. The authors revealed that both physical and verbal attacks were more common on general wards than on psychiatry/geriatric psychiatry wards. These differences, according the authors, may have resulted from the fact that employees working in psychiatry wards had taken part in de-escalation training. Furthermore, the authors stated that where the institution provided good preparation for its staff regarding violent acts, the employees' perception of stress decreased. These findings once again highlight the necessity of implementing programs targeted at the prevention and de-escalation of aggressive behaviours.

In their study, Roche et al. [5] and Kowalczuk et al. [28] revealed that acts of violence towards nurses were most frequently committed by patients, which was consistent with the results presented in this study. As the authors were able to demonstrate, the situation was different in Turkey, where patients' relatives were found to be the main perpetrators - probably due to cultural differences. These findings regarding Turkey are supported by numerous studies from various countries (Turkey included) where whole families accompany patients when an accident occurs and where the relationships among family members are usually very strong [22,29-31].

As far as the reporting of violent incidents is concerned, the majority of authors say that nurses do not report violent incidents, believing that such reporting does not make any difference or that it is just an empty gesture $[5,29,32,33]$. Moreover, they may believe that in work settings where violence is potentially expected, such incidents can be seen as a sign of incompetence. According to some executives, such reports might also have a negative effect on patients' satisfaction reports [16]. In the present study, half of the study group believed that reporting a physical attack or verbal abuse would be useless. About $40 \%$ of the participants believed that violent acts in the workplace were not important, especially among nurses from psychiatric wards and hospices, homes for the elderly/ nursing homes and rehabilitation centres/convalescent homes. This means that they considered exposure to violence to be part of a carer's job. Notably, nurses should begin to believe that it obviously is not. In 2006, the ICN published a position statement entitled "Abuse and violence against nursing personnel" which supports the view that every single nurse has the right to personal dignity and integrity, as well as to freedom from harm [34]. By using the "do nothing and keep silent" coping method, nurses give the perpetrators of violence a clear sign that this behaviour is acceptable. This way of coping with violent attacks merely sweeps the problem under the carpet and can leave thousands of nurses at further risk each year. It is noteworthy that Schablon et al. [19] presented promising data regarding the reporting of violent behaviours by healthcare workers. According to the authors, as many 
as $55 \%$ of the study participants stated that their institutions systematically recorded violent acts, and $85 \%$ reported such events to their superiors. The authors of this study concluded that healthcare institutions deal more openly with the topic of violence. Moreover, only when this topic is no longer considered taboo can preventive programs really be effective.

It is disturbing that although $69 \%$ of the participants knew there were some reporting procedures in place, only $23 \%$ knew how to use them. Nursing managers need to recognize that however challenging it may be, it really is their job to spread information about violence risk factors, to provide support to victims of violence, and to provide guidance about avenues for seeking help. Some findings in the literature indicate that support after violent acts can lead to a reduction in future violence [35,36]. This study revealed that about $70 \%$ of violent acts were not investigated further at all. Compared with other studies [30], this result is much higher. On the other hand, it is promising that managers in the present study were perceived as the main source for starting investigations on behalf of nurses after both physical $(56 \%)$ and nonphysical $(72 \%)$ attacks. Leaders are supposed to take further action and report this fact to their superiors, but whether they do so or not is left to their judgement [37]. This could be a possible explanation for the relatively high ratio of nurses who are dissatisfied with the manner in which violent incidents are handled.

\section{Study limitations}

This study has several limitations. The first limitation lies in the way the study sample was collected and in the relatively small sample size. Due to the difficulties in obtaining approval from private healthcare providers, the authors decided not to include this health sector in the study sample. However, it can be assumed that the inclusion of this sector in the survey could strengthen the reliability of the results. Nonetheless, sampling bias was reduced by the inclusion of all major healthcare settings that represent national health systems, and all major disciplines within the healthcare settings. Further, the national samples were relatively small, which could hinder the generalisation of the results.

Self-assessment is another limiting factor. The obtained retrospective data may be biased since the violent incidents might be misremembered. To minimize recall bias, the authors adapted an approach successfully used in previous studies on work-related violence and asked the participants to limit their recall to the past 12 months.

The third limitation concerns the possible misunderstanding of the terms physical and non-physical violence. To avoid this problem, each questionnaire was accompanied by a covering letter in which the participants were informed about the aim of the study and given a glossary of terms (especially what physical violence refers to and how psychological violence is defined).

\section{CONCLUSIONS}

To conclude, nurses internationally are exposed to workplace violence, especially to non-physical forms. The most obvious way to cope with violence in the workplace is to create a culture of recognizing, addressing and preventing the problem. In a work environment where nurses feel a "zero tolerance" policy is in place, where an effective reporting system exists, staff are trained, and managers are engaged and give nurses support, the reporting ratio will also be better. However, it was shown that about half of the participants do not report violent incidents, believing it to be useless or simply not important. These findings are alarming, yet not altogether surprising when the challenges that exist in the healthcare world are taken into account. In fact, these challenges often limit staff's ability to report violent acts. The results of this study should ideally contribute to the development of efficiently functioning national systems of reporting workplace violence towards nurses in the participating countries. 


\section{REFERENCES}

1. Campos A, Pierantoni CR. Violence in the health care workplace: a theme for international cooperation in human resources in the health sector. R Eletr de Com Inf Inov Saúde. 2010;4:79-85, https://doi.org/10.3395/reciis.v4i1.349en.

2. World Health Organization [Internet]. Geneva: The Organization: 2004 [cited 2019 Mar 1]. Butchart A, Phinney A, Check P, Villaveces A. Preventing violence: a guide to implementing the recommendations of the World report on violence and health. Department of Injuries and Violence Prevention. Available from: https://apps.who.int/iris/bitstream/ handle/10665/43014/9241592079.pdf.

3. Eurofound [Internet]. Dublin: The Organization: 2015 [cited 2019 Mar 1]. Violence and harassment in European workplaces: extent, impacts and policies. Available from: https:// www.eurofound.europa.eu/sites/default/files/ef_comparative_analytical_report/field_ef_documents/ef1473en.pdf.

4. Essenmacher L, Aranyos D, Upfal M, Russell J, Luborsky M, Ager J, et al. Understanding underreporting: comparison of self-report and actual documentation of workplace violence events in hospital settings. In: Needham I, Kingma M, McKenna K, Frank O, Tuttas C, Kingma S, et al., editors. Violence in the Health Sector. Proceedings of the Fourth International Conference on violence in the health sector towards safety, security and wellbeing for all; 2014 Oct 22-24. Amsterdam: Kavanah, Dwingeloo \& Oud Consultancy: 2014. p. 170-1.

5. Roche M,DiersD,DuffieldC,Catling-PaullC. Violence toward nurses, the work environment and patient outcomes. J Nurs Sch. 2010;42(1):13-22, https://doi.org/10.1111/j.1547-5069. 2009.01321.x.

6. Kvas A, Seljak J. Unreported workplace violence in nursing. Int Nurs Rev. 2014;61:344-51, https://doi.org/10.1111/inr. 12106.

7. Ray MM. The dark side of the job: violence in the emergency department. J Emerg Nurs. 2007;33:257-61, https://doi. org/10.1016/j.jen.2007.01.015.

8. Gal M, Timofe MP, Rus D, Zavtochi ES, Boeriu C, Cherechesset RM, et al. Emergency health care violence: who is at risk? Evidence from a large Emergency Department in Mureş County, Romania. Eur J Public Health. 2013;23 Suppl 1:164, https://doi.org/10.1093/eurpub/ckt123.044.

9. International Labour Office, International Council of Nurses, World Health Organization, International PS [Internet]. Geneva: The Organization: 2002 [cited 2019 Mar 1]. Framework guidelines for addressing workplace violence in the health sector. Available from: https:/apps.who.int/iris/bitstream/handle/10665/42617/9221134466.pdf? sequence $=1$.

10. International Labour Office, International Council of Nurses, World Health Organization, International PS [Internet]. Geneva: The Organization; 2003 [cited 2019 Mar 1]. Workplace violence in the health sector country case studies research instruments survey questionnaire. English. Available from: https://www.who.int/violence_injury_prevention/violence/interpersonal/en/WVquestionnaire.pdf.

11. Sperber AD. Translation and validation of study instruments for cross-cultural research. Gastroenterol. 2004;126:124-8, https://doi.org/10.1053/j.gastro.2003.10.016.

12. Viotti S, Gilardi S, Guglielmetti C, Converso D. Verbal aggression from care recipients as a risk factor among nursing staff: a study on burnout in the JD-R model perspective. BioMed Res Int. 2015, https://doi.org/10.1155/2015/215267.

13. Yao Y, Wang W, Wang F, Yao W. General self-efficacy and the effect of hospital workplace violence on doctors' stress and job satisfaction in China. Int J Occup Med Environ Health. 2014;27(3): 389-99, https://doi.org/10.2478/s13382-014-0255-y.

14. Papa A, Venella J. Workplace violence in healthcare: strategies for advocacy. Online J Issues Nurs. 2013;18(1):5.

15. Magnavita N, Heponiemi T. Violence towards health care workers in a public health care facility in Italy: a repeated cross-sectional study. BMC Health Serv Res. 2012;12:108, https://doi.org/10.1186/1472-6963-12-108.

16. Gates DM, Gillespie GL, Succop P. Violence against nurses and its impact on stress and productivity. Nurs Econ. 2011;29:59-66.

17. Estryn-Behar M, van der Heijden B, Camerino D, Fry C, Le Nezet O, Conway PM, et al. Violence risks in nursing-results 
from the European 'NEXT’ study. Occup Med. 2008;58:10714, https://doi.org/10.1093/occmed/kqm142.

18. Magnavita N. The exploding spark. Workplace violence in an infectious disease hospital - a longitudinal study. Biomed Res Int. 2013;2013:316358, https://doi.org/10.1155/2013/316358.

19. Schablon A, Wendeler D, Kozak A, Nienhaus A, Steinke S. Prevalence and consequences of aggression and violence towards nursing and care staff in Germany - a survey. Int J Environ Res Publ Health. 2018;15(6):E1274, https://doi. org/10.3390/ijerph15061274.

20. Magnavita N. Violence prevention in a small-scale psychiatric unit. Program planning and evaluation. Int J Occup Environ Health. 2011;17(4):336-44.

21. Chirico F, Heponiemi T, Pavlova M, Zaffina S, Magnavita N. Psychosocial risk prevention in a global occupational health perspective. A descriptive analysis. Int J Environ Res Public Health. 2019;16(14):E2470, https://doi.org/10.3390/ijerph 16142470.

22. Pinar T, Cengizhan A, Gul P, Erdem K, Meral S, Elif B, et al. Workplace violence in the health sector in Turkey. Eur J Public Health. 2013;23(Suppl 1):150, https://doi.org/10.1093/ eurpub/ckt123.011.

23. Talas MS, Kocaöz S, Akgüç S. A survey of violence against staff working in the emergency department in Ankara, Turkey. Asian Nurs Res. 2011;5:197-203, https://doi. org/10.1016/j.anr.2011.11.001.

24. Fisekovic MB, Trajkovic GZ, Bjegovic-Mikanovic VM, Terzic-Supic ZJ. Does workplace violence exist in primary health care? Evidence from Serbia. Eur J Public Health 2015; 25(4):693-8, https://doi.org/10.1093/eurpub/cku247.

25. Pompeii L, Schoenfisch A, Lipscomb H, Dement J, Smith C, Upadhyaya M. Workplace violence: What gets reported by workers in this culture of caring? In: Needham I, Kingma M, McKenna K, Frank O, Tuttas C, Kingma S, et al., editors. Violence in the Health Sector. Proceedings of the Fourth International Conference on violence in the health sector towards safety, security and wellbeing for all; 2014 Oct 22-24. Amsterdam: Kavanah, Dwingeloo \& Oud Consultancy: 2014. p. 187-8.
26. Privitera M, Weisman R, CerulliC, Tu X, Groman A. Violence toward mental health staff and safety in the work environment. Occup Med. 2005;55:480-6, https://doi.org/10.1093/ occmed/kqi110.

27. Virtanen M, Vahtera J, Batty GD, Tuisku K, Oksanen T, Elovainio $\mathrm{M}$, et al. Health risk behaviors and morbidity among hospital staff - comparison across hospital ward medical specialties in a study of 21 Finnish hospitals. Scand J Work Environ Health. 2012;38(3):228-37, https://doi.org/10.5271/sjweh.3264.

28. Kowalczuk K, Jankowiak B, Krajewska-Kułak B, van DammeOstapowicz K, Kowalewska B. Comparison of the level of aggression towards healthcare workers within Podlaskie Voivodeship. Int J Occup Med Environ Health. 2011;24(3): 267-74, https://doi.org/10.2478/s13382-011-0024-0.

29. Shoghi M, Sanjari M, Shirazi F, Heidari S, Salemi S, Mirzabeigi G. Workplace violence and abuse against nurses in hospitals in Iran. Asian Nurs Res. 2008;2:184-93, https://doi. org/10.1016/S1976-1317(08)60042-0.

30. Zafar W, Siddiqui E, Ejaz K, Shehzad MU, Khan UR, Jamali S, et al. Health care personnel and workplace violence in the emergency departments of a volatile metropolis: results from Karachi, Pakistan. J Emerg Med. 2013;45:761-72, https://doi.org/10.1016/j.jemermed.2013.04.049.

31. AbuAlRub RF, Talal Al Khaaldeh A. Workplace physical violence among hospital nurses and physicians in underserved areas in Jordan. J Clin Nurs. 2013;23:1937-47, https://doi. org/10.1111/jocn.12473.

32. Chapman R, Styles I, Perry L, Combs S. Examining the characteristics of workplace violence in one hospital. J Clin Nurs. 2009;19(3-4):479-88, https://doi.org/10.1111/j.1365-2702. 2009.02952.x.

33. Arnetz JE, Hamblin L, Ager J, Luborsky M, Upfal MJ, Russell J, et al. Underreporting of workplace violence: comparison of self-report and actual documentation of hospital incidents. Workplace Health Saf. 2015;63(5):200-10, https://doi. org/10.1177/2165079915574684.

34. ICN: International Council of Nurses [Internet]. Geneva: The Organization; 2006 [cited 2019 Mar 16]. Abuse and 
violence against nursing personnel. Available from: https:// static1.squarespace.com/static/579770cd197aea84455d6908/ t/57d86320d1758e16f4e0f202/1473798944490/C01_Abuse_ Violence_Nsg_Personnel.pdf.

35. Findorff MJ, McGovern PM, Wall M, Gerberich SG, Alexander B. Risk factors for work related violence in a health care. Inj Prev. 2004;10:296-302, https://doi.org/10.1136/ip. 2003.004747.

36. Casselman N, Bujna E, Wardrope S. Workplace violence prevention and leadership engagement: the collaboration between a large community hospital and union. In: Needham I, Kingma M, McKenna K, Frank O, Tuttas C, Kingma S, et al., editors. Violence in the Health Sector. Proceedings of the Fourth International Conference on violence in the health sector towards safety, security and wellbeing for all; 2014 Oct 22-24. Amsterdam: Kavanah, Dwingeloo \& Oud Consultancy: 2014. p. 420-4.

37. Dillon BL. Workplace violence: impact, causes, and prevention. Work. 2012;42(1):15-20, https://doi.org/10.3233/WOR2012-1322.

This work is available in Open Access model and licensed under a Creative Commons Attribution-NonCommercial 3.0 Poland License - http://creativecommons.org/ licenses/by-nc/3.0/pl/deed.en. 